\title{
Concomitant mitral repair and continuous-flow left ventricular assist devices: Is it warranted?
}

\author{
Shinichi Fukuhara, MD, ${ }^{\mathrm{a}}$ Koji Takeda, MD, PhD, ${ }^{\mathrm{a}}$ Codruta Chiuzan, PhD, ${ }^{\mathrm{b}}$ Jiho Han, BS, ${ }^{\mathrm{a}}$ \\ Paul A. Kurlansky, MD, ${ }^{a}$ Hiroo Takayama, $\mathrm{MD}, \mathrm{PhD},{ }^{\mathrm{a}}$ and Yoshifumi Naka, MD, $\mathrm{PhD}^{\mathrm{a}}$
}

\section{ABSTRACT}

Background: Pre-existing mitral pathology is common in patients undergoing continuous-flow left ventricular assist device implantation. We sought to investigate whether concurrent mitral repair confers any advantage.

Methods: From March 2004 to October 2014, 374 patients received a continuousflow left ventricular assist device. Of these, a total of 115 patients with preexisting mitral regurgitation (MR) greater than moderate were identified and included in the analysis. Outcomes were compared between patients with concurrent mitral repair $(n=52$ [45.2\%]; Group A) and without repair $(n=63$ [54.8\%]; Group B).

Results: The mean age was 56.8 years and $25(21.5 \%)$ were women. Patients in Group A were more likely to have undergone destination therapy $(48.1 \%$ vs $11.1 \% ; P<.001)$ and had a greater cardiopulmonary bypass time (125 vs $89 \mathrm{mi}-$ nutes; $P<.001$ ) than did patients in Group B. Longitudinal analysis using a generalized mixed-effects model demonstrated the odds of developing moderate or severe MR during device support were $86 \%$ lower for Group A patients $(P<.001)$. Among those who were discharged alive, $9(8.6 \%)$-consisting of 1 $(2.2 \%)$ in Group A and $8(13.6 \%)$ in Group B $(P=.039)$-developed late right heart failure requiring a total of 13 readmissions $(0.03$ vs 0.15 readmissions per patient-year; $P=.011)$. Multivariable competing risks regression revealed mitral repair to be a protective factor (hazard ratio, 0.16 ; $95 \%$ confidence interval, 0.03 $0.94 ; P=.042$ ) for late right heart failure occurrence.

Conclusions: Concurrent mitral repair appears to be efficacious in controlling MR after device implant. The fact that repaired patients developed late right heart failure less frequently than did patients without repair challenges the notion that concurrent mitral repair is unwarranted. (J Thorac Cardiovasc Surg 2017;154:1303-12)

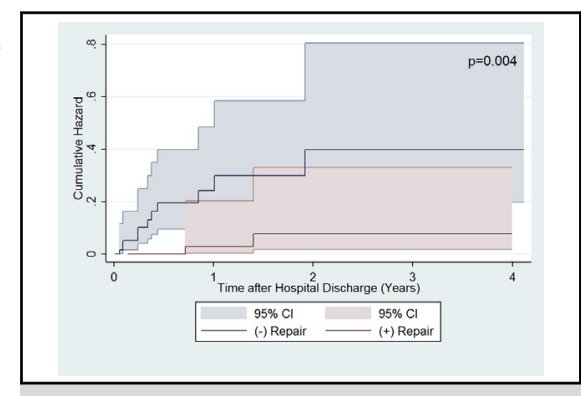

Late right heart failure occurrence in patients with mitral repair versus without repair.

\section{Central Message}

Concurrent mitral repair appears to be efficacious in controlling mitral regurgitation after device implant with less frequent late right heart failure compared with patients without repair.

\section{Perspective}

Pre-existing mitral pathology is common in patients receiving a continuous-flow left ventricular assist device, whereas clinical implication of concurrent repair is unknown. Concurrent repair appears to be efficacious in controlling mitral regurgitation postimplant with less frequent late right heart failure compared with patients without repair, challenging the notion that concurrent repair is unwarranted.

See Editorial Commentary page 1313.
With the evolution of technology and patient management, continuous-flow left ventricular assist device (CFLVAD) use has grown rapidly. ${ }^{1}$ In this context, the

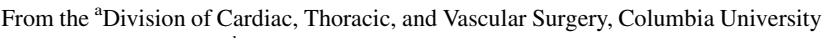
Medical Center; and ${ }^{\mathrm{b}}$ Department of Biostatistics, Columbia University Mailman School of Public Health, New York, NY.

Received for publication Sept 28, 2016; revisions received March 19, 2017; accepted for publication April 10, 2017; available ahead of print Aug 8, 2017

Address for reprints: Yoshifumi Naka, MD, PhD, Division of Cardiac, Thoracic, and Vascular Surgery, Columbia University Medical Center, 177 Fort Washington Ave, New York, NY 10032 (E-mail: yn33@cumc.columbia.edu). $0022-5223 / \$ 36.00$

Copyright (C) 2017 Published by Elsevier Inc. on behalf of The American Association for Thoracic Surgery

http://dx.doi.org/10.1016/j.jtcvs.2017.04.021
}

management of pre-existing valvular lesions has become a subject of interest. The management of native valve dysfunction in CF-LVAD recipients has been discussed mainly with regard to aortic and tricuspid valves. ${ }^{2-4} \mathrm{By}$ contrast, pre-existing mitral pathology and its clinical influence has not been extensively investigated, despite being the most prevalent valvular pathology. ${ }^{5}$ The

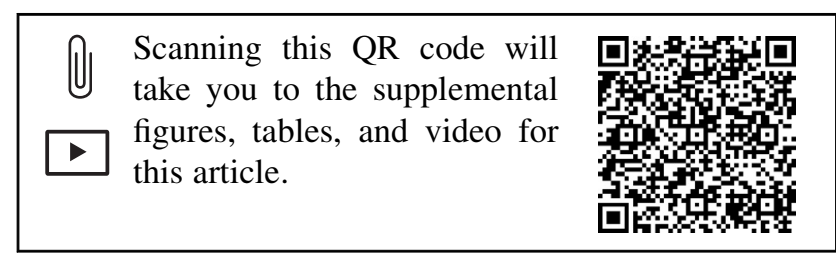




Abbreviations and Acronyms
$\begin{aligned} \text { BMI } & =\text { body mass index } \\ \text { CF-LVAD }= & \text { continuous-flow left ventricular assist } \\ & \text { device } \\ \text { CPB } \quad= & \text { cardiopulmonary bypass } \\ \text { LV } & =\text { left ventricle } \\ \text { MR } & =\text { mitral regurgitation } \\ \text { RHF } & =\text { right heart failure } \\ \text { RV } & =\text { right ventricle } \\ \text { RVAD } & =\text { right ventricular assist device }\end{aligned}$

mechanism of mitral regurgitation (MR) in most patients receiving device therapy is functional, resulting from tethering of the leaflets secondary to left ventricular (LV) dilatation and a change in geometry from an elliptical to spherical shape. ${ }^{2,6,7}$ With device decompression, LV dimensions decrease and allow mitral leaflets to coapt, making MR insignificant in most patients. ${ }^{8}$ Furthermore, the severity of pre-existing MR does not necessarily provide independent prognostic information. ${ }^{5}$ The current consensus statement does not recommend concomitant mitral interventions, regardless of severity, unless there is expectation of ventricular recovery. ${ }^{9}$ However, it is of critical importance to note that previous studies were lacking a surgical control group. Therefore, it remains unclear whether patients with pre-existing MR would benefit from repair at device insertion. We have reviewed our experience of CF-LVAD implantation with and without mitral repair to demonstrate the outcomes and ultimately elucidate its clinical implications.

\section{METHODS}

The Columbia University Institutional Review Board approved all aspects of the study.

\section{Patients and Study Design}

We retrospectively reviewed 374 consecutive patients who underwent CF-LVAD implantation between March 2004 and October 2014. Of these, 35 patients with previous mitral procedures and 1 with concomitant mitral replacement were excluded. A total of 115 patients with baseline pre-existing MR greater than moderate were identified and included in the analysis. Patients were grouped into Group A (52 [45.2\%] with concomitant mitral repair) and Group B (63 [54.8\%] without repair). Abstracted data included the following: patient demographic, clinical, and treatment variables, cardiopulmonary bypass (CPB) time, blood product use, dose of vasoactive drugs at device implantation, perioperative and follow-up echocardiographic variables, adverse events, and survival. Follow-up was completed as of July 1, 2015 , with a completion rate of $98.3 \%$. The types of CF-LVADs implanted comprise HeartMate II (Thoratec, Pleasanton, Calif) $(\mathrm{n}=86$; $74.8 \%$ ), HeartWare HVAD (HeartWare Inc, Framingham, Mass) ( $\mathrm{n}=21 ; 18.3 \%$ ), Ventrassist (Ventracor Ltd, Chatswood, New South Wales, Australia) $(\mathrm{n}=3 ; 2.6 \%)$, DuraHeart (TerumoHeart, Ann Arbor, Mich) $(\mathrm{n}=2 ; 1.7 \%)$, and DeBakey VAD (MicroMed Technology Inc, Houston, Tex) $(\mathrm{n}=3 ; 2.6 \%)$.

\section{Assessment of MR}

Details of our protocol have been reported elsewhere. ${ }^{10,11}$ In brief, serial transthoracic echocardiography and intraoperative transesophageal echocardiography evaluations, reviewed by the same echocardiographers at our institution, were performed in all patients. The presence of MR was determined at baseline before device implant, and until time of last follow-up or censoring event as clinically indicated. Each valve was evaluated visually in the parasternal short- and long-axis views by transthoracic echocardiography and was graded as none, trace, mild, mild-moderate, moderate, moderate-severe, and severe on an interval scale based on the color flow jet according to the recommendations of the American Society of Echocardiography. ${ }^{12}$ Regarding speed optimization, we followed the current recommendations ${ }^{13}$ to ensure middle interventricular septum position and intermittent aortic valve opening while attempting to maintain less-than-mild MR.

\section{Right Heart Failure Definition and Management}

Right heart failure (RHF) during index hospitalization was captured using the Interagency Registry for Mechanically Assisted Circulatory Support definition. ${ }^{14}$ Late RHF was defined as RHF requiring rehospitalization after indexed hospital discharge and medical/surgical treatments, including strengthening of diuretics, inotropic support, and right ventricular assist device (RVAD). ${ }^{15,16}$

Patients who were hospitalized due to symptoms of heart failure routinely underwent interrogation of the device and hemolysis workup to rule out device failure and thrombosis, implantable cardioverterdefibrillator/pacemaker interrogation to identify presence of arrhythmia that may have exacerbated RHF, and echocardiography for optimization of pump speed. Initial medical management included intensification of diuretic therapy. Patients with severe RHF, as defined by the presence of end-organ dysfunction, underwent right heart catheterization, with inotropic therapy initiated if needed. In patients with medically refractory RHF, RVAD implantation was then considered. ${ }^{15,16}$

Detection of late RHF was based on clinical findings, including edema, weight gain, ascites, and jugular venous distention. Heart failure related to device failure, such as device thrombosis, inflow and outflow obstruction, or drive-line fracture, was not considered late RHF.

\section{Indications and Operative Technique of Mitral Repair}

The indication for mitral repair is pre-existing MR greater than moderate. The decision to perform a repair was based on clinical characteristics in each patient, essentially bridge-to-transplant patients with anticipated prolonged device support (such as blood type $\mathrm{O}$, large body size with body mass index $[\mathrm{BMI}]>35$ ) and patients with destination therapy intent at time of device insertion.

Tricuspid repair was performed for moderate or greater tricuspid regurgitation. ${ }^{4}$ Tricuspid ring annuloplasty was the first choice of procedure. In the case of severe leaflet tethering or destruction, tricuspid replacement was performed with a bioprosthetic valve.

Annuloplasty. This is our preferred approach for repair. After establishing CPB with standard aortobicaval cannulation, mitral repair was performed with a beating heart. A standard right-sided left atriotomy was made. A commercially available annuloplasty ring (Table 1) was implanted using interrupted 2-0 polyester sutures placed circumferentially around the annulus in mattress fashion (Figure E1, $A$ ). The annulus was usually undersized by 2 sizes. The atriotomy was then closed.

Edge-to-edge repair. Edge-to-edge repair (Alfieri stitch) ${ }^{17}$ was chosen when other concomitant valve repair/other procedures were performed or ring annuloplasty was not possible due to severe mitral annular calcification. For instance, when concomitant aortic valve repair was performed, CPB was established with the standard aortoatrial cannulation followed by aortic crossclamping and cardioplegia administration. A central 
TABLE 1. Intraoperative data

\begin{tabular}{|c|c|c|c|c|c|}
\hline \multicolumn{2}{|c|}{ Variable } & $(+)$ Repair $(\mathbf{n}=\mathbf{5 2})$ & \multicolumn{2}{|c|}{$(-)$ Repair $(n=63)$} & $P$ value \\
\hline \multicolumn{6}{|l|}{ Implanted device } \\
\hline \multicolumn{2}{|l|}{ HeartMate II* } & $39(75.0)$ & \multicolumn{2}{|c|}{47 (74.6) } & .96 \\
\hline \multicolumn{2}{|l|}{ HeartWare $\dagger$} & $13(25.0)$ & \multicolumn{2}{|c|}{$8(12.7)$} & .089 \\
\hline \multicolumn{2}{|l|}{ Ventrassist $\ddagger$} & 0 & \multicolumn{2}{|c|}{$3(4.8)$} & \\
\hline \multicolumn{2}{|l|}{ DuraHeart $\S$} & 0 & \multicolumn{2}{|c|}{$2(3.2)$} & \\
\hline \multicolumn{2}{|l|}{ DeBakey VAD } & 0 & \multicolumn{2}{|c|}{$3(4.8)$} & \\
\hline \multicolumn{6}{|c|}{ Other concomitant procedures } \\
\hline \multicolumn{2}{|c|}{ Aortic valve repair } & $13(28.9)$ & \multicolumn{2}{|c|}{$10(16.9)$} & .15 \\
\hline Tricuspid repai & & $12(23.1)$ & \multicolumn{2}{|c|}{$18(28.6)$} & .50 \\
\hline TVR & & $3(5.8)$ & \multicolumn{2}{|c|}{$1(1.6)$} & .63 \\
\hline PFO closure & & $1(1.9)$ & \multicolumn{2}{|c|}{$3(4.8)$} & .63 \\
\hline CABG & & $1(1.9)$ & \multicolumn{2}{|c|}{0} & .45 \\
\hline RVAD implant & & $3(5.8)$ & \multicolumn{2}{|c|}{$1(1.6)$} & .33 \\
\hline \multirow{2}{*}{\multicolumn{2}{|c|}{$\begin{array}{l}\mathrm{CPB} \text { time, } \min \\
\text { Isolated mitral repair vs no repair }\end{array}$}} & $125.0 \pm 35.1$ & \multirow{2}{*}{\multicolumn{2}{|c|}{$\begin{array}{c}89.4 \pm 42.0 \\
65.9 \pm 39.9(\mathrm{n}=35)\end{array}$}} & $<.001 \|$ \\
\hline & & $117.6 \pm 31.6(\mathrm{n}=28)$ & & & $<.001 \|$ \\
\hline \multicolumn{6}{|l|}{ Transfusions, units } \\
\hline \multicolumn{2}{|c|}{ Packed red blood cell } & $2.1 \pm 2.8$ & \multicolumn{2}{|c|}{$1.6 \pm 2.4$} & .29 \\
\hline \multicolumn{2}{|c|}{ Fresh frozen plasma } & \multirow{2}{*}{$\begin{array}{c}3.4 \pm 2.8 \\
10.5 \pm 6.6\end{array}$} & \multicolumn{2}{|c|}{$3.1 \pm 3.2$} & .65 \\
\hline Platelet & & & \multicolumn{2}{|c|}{$8.9 \pm 7.1$} & .22 \\
\hline \multicolumn{2}{|c|}{ Vasoactive-inotropic score $\llbracket$} & $20.5 \pm 13.9$ & & & .15 \\
\hline & Ring annulo| & $y(n=34)$ & Edge-to- & $=18)$ & \\
\hline No. of patients & Cosgrove-Edwards\# & $20(58.8)$ & LV apex & $8(44.4)$ & \\
\hline & SJM Saddle Ring*** & $7(20.6)$ & Aortotomy & $4(22.2)$ & \\
\hline & Profile 3D Ring $\dagger \dagger$ & $4(11.8)$ & Left atriotomy & $4(22.2)$ & \\
\hline & GeoForm Ring\# & $3(8.8)$ & Transseptal & $2(11.1)$ & \\
\hline CPB time, min & & & & & \\
\hline All & $134.5 \pm 34.5$ & & $111.2 \pm 30.8$ & & $.020 \|$ \\
\hline Isolated repair & $120.8 \pm 31.5$ & & $102.6 \pm 31.1$ & & .25 \\
\hline
\end{tabular}

Values are presented as n (\%) or mean \pm standard error. $V A D$, Ventricular assist device; $T V R$, tricuspid valve replacement; $P F O$, patent foramen ovale; $C A B G$, coronary artery bypass graft; $R V A D$, right ventricular assist device; $C P B$, cardiopulmonary bypass; $L V$, left ventricle; SJM, St Jude Medical. *Thoratec, Pleasanton, Calif. $\dagger$ HeartWare, Framingham, Mass. †Ventracor Ltd, Chatswood, Australia. §TerumoHeart, Ann Arbor, Mich. $\|$ Statistically significant values $(P<.05)$. 9 Vasoactive-inotropic score $=$ dopamine dose $(\mu \mathrm{g} /$ $\mathrm{kg} / \mathrm{min})+$ dobutamine dose $(\mu \mathrm{g} / \mathrm{kg} / \mathrm{min})+100 \times$ epinephrine dose $(\mu \mathrm{g} / \mathrm{kg} / \mathrm{min})+10 \times$ milrinone dose $(\mu \mathrm{g} / \mathrm{kg} / \mathrm{min})+10,000 \times$ vasopressin dose $(\mathrm{U} / \mathrm{kg} /$ $\min )+100 \times$ norepinephrine dose $(\mu \mathrm{g} / \mathrm{kg} / \mathrm{min}) .{ }^{21}$ \#Edwards Lifesciences, Irvine, Calif. $* *$ St Jude Medical, St Paul, Minn. $\dagger \dagger$ Medtronic, Minneapolis, Minn.

edge-to-edge stitch (Alfieri stitch) using 2-0 polyester sutures with or without pledgets was placed approximately $10 \mathrm{~mm}$ away from the free edges of A2 and P2 through the transverse aortotomy (Figure E1, B). The aortic valve repair was then performed. The rest of the procedure was conducted in the usual fashion ${ }^{18}$ after aortotomy closure and unclamping. This repair was also performed through the LV apex after coring for the inflow cannula placement or transseptally when concomitant tricuspid procedure was performed.

\section{Statistical Analysis}

Continuous variables were expressed as mean \pm 1 standard deviation. Categorical variables were presented as proportions and absolute numbers. Differences were detected using $\chi^{2}$ or Fisher exact test for categorical and the Mann-Whitney $U$ or Student $t$ test for continuous variables. The survival was estimated using Kaplan-Meier method and compared with log-rank test. Patients were censored for transplant or device explant. Preimplant clinical parameters were analyzed to determine contributing factors for late RHF using the competing risks regression methods of Fine and Gray ${ }^{19}$ to account for competing events, which were death and transplant. For multivariable analysis, variables with a $P$ value $\leq .25$ on univariable analysis were included into a final model. In addition, due to the small number of events, concomitant tricuspid repair and baseline pulmonary vascular resistance were also included as surrogates of baseline right ventricle (RV) function by clinical judgment. Results are presented as hazard ratios (HRs) with corresponding 95\% confidence intervals (CIs). For longitudinal data analysis, a mixed-effects logistic regression model with a logit link was employed to assess the association between treatment and MR severity. ${ }^{20}$ The final models included fixed effects for treatment group, time (continuous scale), and a random effect to account for within-subject variation. To satisfy the linearity assumption, a log transformation was applied to the time variable. In addition, a time $\times$ group interaction was tested, but found to be statistically nonsignificant. All $P$ values were results of 2-tailed tests. The statistical analysis was performed using SPSS 22.0 (IBM-SPSS Inc, Armonk, NY), Stata 14.2 (StataCorp, College Station, Tex), and SAS 9.4 (SAS Institute Inc, Cary, NC).

\section{RESULTS}

\section{Patient Demographic Characteristics}

Patient demographic characteristics are shown in Table 2. The mean age was 56.8 years and $25(21.7 \%)$ were women. 
TABLE 2. Predevice implantation clinical characteristics

\begin{tabular}{|c|c|c|c|}
\hline Patient demographic characteristic & $(+)$ Repair $(n=52)$ & $(-)$ Repair $(n=63)$ & $P$ value \\
\hline Female gender & $14(26.9)$ & $11(17.5)$ & .21 \\
\hline Mean age, y & $58.5 \pm 13.9$ & $55.5 \pm 13.3$ & .24 \\
\hline \multicolumn{4}{|l|}{ Race or ethnicity } \\
\hline Nonwhite & $32(61.5)$ & $34(54.0)$ & .41 \\
\hline $\begin{array}{l}\text { Body mass index } \\
\quad>35\end{array}$ & $\begin{array}{c}26.3 \pm 6.6 \\
5(9.6)\end{array}$ & $\begin{array}{c}25.9 \pm 5.1 \\
1(1.6)\end{array}$ & $\begin{array}{l}.76 \\
.054\end{array}$ \\
\hline $\begin{array}{l}\text { Etiology } \\
\text { Ischemic cardiomyopathy } \\
\text { Dilated cardiomyopathy } \\
\text { Others }\end{array}$ & $\begin{array}{c}18(34.6) \\
32(61.5) \\
2(3.8)\end{array}$ & $\begin{array}{c}18(28.6) \\
40(63.5) \\
5(7.9)\end{array}$ & .59 \\
\hline $\begin{array}{l}\text { Device intent at insertion } \\
\text { BTT } \\
\text { DT } \\
\text { Undetermined }\end{array}$ & $\begin{array}{c}4(7.7) \\
27(51.9) \\
21(40.4)\end{array}$ & $\begin{array}{r}44(69.8) \\
10(15.9) \\
9(14.3)\end{array}$ & $<.001^{*}$ \\
\hline $\begin{array}{l}\text { Device intent at most recent follow-up } \\
\text { BTT } \\
\text { DT }\end{array}$ & $\begin{array}{l}27(51.9) \\
25(48.1)\end{array}$ & $\begin{array}{r}56(88.9) \\
7(11.1)\end{array}$ & $<.001^{*}$ \\
\hline \multicolumn{4}{|l|}{ Medical comorbidities } \\
\hline Hypertension & $24(46.2)$ & $32(50.8)$ & .62 \\
\hline Dyslipidemia & $19(36.5)$ & $19(30.2)$ & .47 \\
\hline Coronary artery disease & $20(38.5)$ & $23(36.5)$ & .85 \\
\hline Diabetes & $15(28.8)$ & $21(33.3)$ & .61 \\
\hline Chronic obstructive pulmonary disease & $3(5.8)$ & $5(7.9)$ & .65 \\
\hline Prior cardiovascular accident & $5(9.6)$ & $7(11.1)$ & .79 \\
\hline Drug abuse & $5(9.6)$ & $6(9.5)$ & .99 \\
\hline Previous malignancy & $5(9.6)$ & $4(6.3)$ & .94 \\
\hline Smoking & $20(38.5)$ & $19(30.2)$ & .35 \\
\hline \multicolumn{4}{|l|}{ Previous cardiac surgery } \\
\hline Coronary artery bypass graft & $8(15.4)$ & $13(20.6)$ & .47 \\
\hline Aortic valve & 0 & $2(3.2)$ & .50 \\
\hline Ventricular assist device/extracorporeal membrane oxygenation & $2(3.8)$ & $4(6.3)$ & 69 \\
\hline Automated implantable cardioverter-defibrillator & $42(80.8)$ & $52(82.5)$ & .81 \\
\hline Others & $2(3.8)$ & $3(4.8)$ & .80 \\
\hline Intra-aortic balloon pump & $16(30.8)$ & $17(27.0)$ & .66 \\
\hline Inotrope & $44(84.6)$ & $54(85.7)$ & .87 \\
\hline Vasopressor & $7(13.5)$ & $3(4.8)$ & .18 \\
\hline Mechanical ventilation & $2(3.8)$ & $1(1.6)$ & .59 \\
\hline \multicolumn{4}{|l|}{ Laboratory values } \\
\hline Blood urea nitrogen, $\mathrm{mg} / \mathrm{dL}$ & $34.4 \pm 19.6$ & $38.0 \pm 18.7$ & .32 \\
\hline Creatinine, $\mathrm{mg} / \mathrm{dL}$ & $1.36 \pm 0.55$ & $1.54 \pm 0.51$ & .065 \\
\hline Albumin, g/dL & $3.6 \pm 0.6$ & $3.7 \pm 0.5$ & .48 \\
\hline Total bilirubin, $\mathrm{mg} / \mathrm{dL}$ & $1.6 \pm 1.2$ & $1.4 \pm 1.0$ & .36 \\
\hline Direct bilirubin, $\mathrm{mg} / \mathrm{dL}$ & $0.7 \pm 0.7$ & $0.5 \pm 0.5$ & .17 \\
\hline Aspartate aminotransferase, U/L & $62.7 \pm 169.9$ & $34.1 \pm 39.9$ & .24 \\
\hline Alanine aminotransferase, $\mathrm{U} / \mathrm{L}$ & $53.4 \pm 135.5$ & $56.7 \pm 149.7$ & .90 \\
\hline Alkaline phosphatase, U/L & $97.8 \pm 59.1$ & $98.5 \pm 50.5$ & .90 \\
\hline Prothromibin time/international normalized ratio & $1.44 \pm 0.52$ & $1.34 \pm 0.35$ & .20 \\
\hline \multicolumn{4}{|l|}{ Hemodynamic parameters } \\
\hline Systolic blood pressure, $\mathrm{mm} \mathrm{Hg}$ & $98.7 \pm 10.1$ & $102.1 \pm 13.8$ & .18 \\
\hline Central venous pressure, $\mathrm{mm} \mathrm{Hg}$ & $10.8 \pm 5.7$ & $11.6 \pm 5.4$ & .50 \\
\hline Mean pulmonary pressure, $\mathrm{mm} \mathrm{Hg}$ & $35.7 \pm 10.8$ & $37.0 \pm 8.2$ & .48 \\
\hline
\end{tabular}


TABLE 2. Continued

\begin{tabular}{|c|c|c|c|}
\hline Patient demographic characteristic & $(+)$ Repair $(\mathbf{n}=\mathbf{5 2})$ & (-) Repair $(n=63)$ & $P$ value \\
\hline Wedge pressure, $\mathrm{mm} \mathrm{Hg}$ & $23.3 \pm 8.1$ & $25.9 \pm 7.7$ & .11 \\
\hline Cardiac index, $\mathrm{L} / \mathrm{min} / \mathrm{m}^{2}$ & $1.8 \pm 0.6$ & $1.5 \pm 0.4$ & .13 \\
\hline Pulmonary vascular resistance, wood units & $4.0 \pm 2.2$ & $3.9 \pm 2.5$ & .95 \\
\hline INTERMACS profiles & & & .43 \\
\hline $1-2$ & $42(80.8)$ & 47 (74.6) & \\
\hline HeartMate $\mathrm{II} \dagger$ risk score & $1.63 \pm 1.02$ & $1.54 \pm 0.70$ & .55 \\
\hline Year of device implantation & & & $<.001^{*}$ \\
\hline 2004-2007 & $1(1.9)$ & $22(34.9)$ & \\
\hline 2008-2011 & $28(53.8)$ & $32(50.8)$ & \\
\hline $2012-2015$ & $23(44.2)$ & $9(14.3)$ & \\
\hline \multicolumn{4}{|l|}{ Baseline echocardiographic characteristic } \\
\hline Left ventricular ejection fraction & $14.0 \pm 5.7$ & $16.2 \pm 5.8$ & .054 \\
\hline Mitral regurgitation degree & & & .23 \\
\hline Moderate-severe & $12(23.0)$ & $9(14.3)$ & \\
\hline Severe & $40(76.9)$ & $54(85.7)$ & \\
\hline Tricuspid regurgitation $\geq$ moderate & $23(44.2)$ & $35(55.6)$ & .23 \\
\hline Moderate & $8(15.4)$ & $18(28.6)$ & \\
\hline Moderate-severe & $3(5.8)$ & $5(7.9)$ & \\
\hline Severe & $12(23.1)$ & $12(19.0)$ & \\
\hline Aortic insufficiency $>$ mild & $5(9.6)$ & $3(4.8)$ & .20 \\
\hline Left ventricular end-systolic diameter, $\mathrm{mm}$ & $65.0 \pm 11.6$ & $68.9 \pm 12.9$ & .25 \\
\hline Left ventricular end-diastolic diameter, mm & $71.7 \pm 11.7$ & $74.4 \pm 12.4$ & .24 \\
\hline
\end{tabular}

Values are presented as $\mathrm{n}(\%)$ or mean \pm standard error. BTT, Bridge-to-transplant; DT, destination therapy; INTERMACS, Interagency Registry for Mechanically Assisted Circulatory Support. *Statistically significant values $(P<.05)$. †Thoratec, Pleasanton, Calif.

Patients in Group A were more likely to be planned for destination therapy than were patients in Group B. There were more patients with BMI $>35$ in Group A, whereas the mean BMI is indifferent. Furthermore, concurrent mitral repair was more often performed in relatively recent patients, with the first in 2007 (there were no destination therapy patients before 2007 in the present study cohort). Otherwise, the groups both displayed similar clinical characteristics.

The baseline echocardiographic variables are further displayed in Table 2. The severity of MR was similar and moderate or greater tricuspid regurgitation was common in both groups.

\section{Intraoperative Data}

Table 1 illustrates the intraoperative data. Implanted device brand and the frequency of other concomitant procedures performed were similar. Subjects in Group A had a greater CPB time than did individuals in Group B. In contrast, the dose of vasoactive drugs, as represented by the vasoactive-inotropic score ${ }^{21}$ and blood product use, were comparable between groups.

Regarding the repair method, $34(65.4 \%)$ received a ring annuloplasty, $15(28.9 \%)$ received an edge-to-edge repair, and $2(3.9 \%)$ received a repair with other techniques. Annuloplasty rings used included the Cosgrove-Edwards Annuloplasty System $(\mathrm{n}=20$ [58.8\%]) (Edwards Lifesciences, Irvine, Calif), SJM Rigid Saddle Ring ( $\mathrm{n}=7$ [20.6\%]) (St Jude Medical Inc, St Paul, Minn), GeoForm Ring ( $\mathrm{n}=3$ [8.8\%]) (Edwards Lifesciences), and Profile 3D Annuloplasty System $(\mathrm{n}=4[11.8 \%])$ (Medtronic, Minneapolis, Minn). The median annuloplasty size was $28 \mathrm{~mm}$ (interquartile range, 26$32 \mathrm{~mm}$ ). As for edge-to-edge repair, almost half were performed through the LV apex. The CPB time was significantly longer in patients with annuloplasty compared with others, but not with isolated ring annuloplasty versus isolated edge-to-edge repair (Table 1).

\section{Adverse Events and Survival}

Early postoperative outcomes and adverse events were summarized in Table E1. There was no difference regarding early postoperative complications between groups. Among discharged patients alive with either HeartMate II or HeartWare device, predischarge pump speed in the repaired patients supported with HeartMate II was significantly lower than that of nonrepaired patients with HeartMate II, whereas no difference among patients with HeartWare between groups. Regarding overall adverse events, more frequent RHF, which is attributable to late RHF occurrence, 

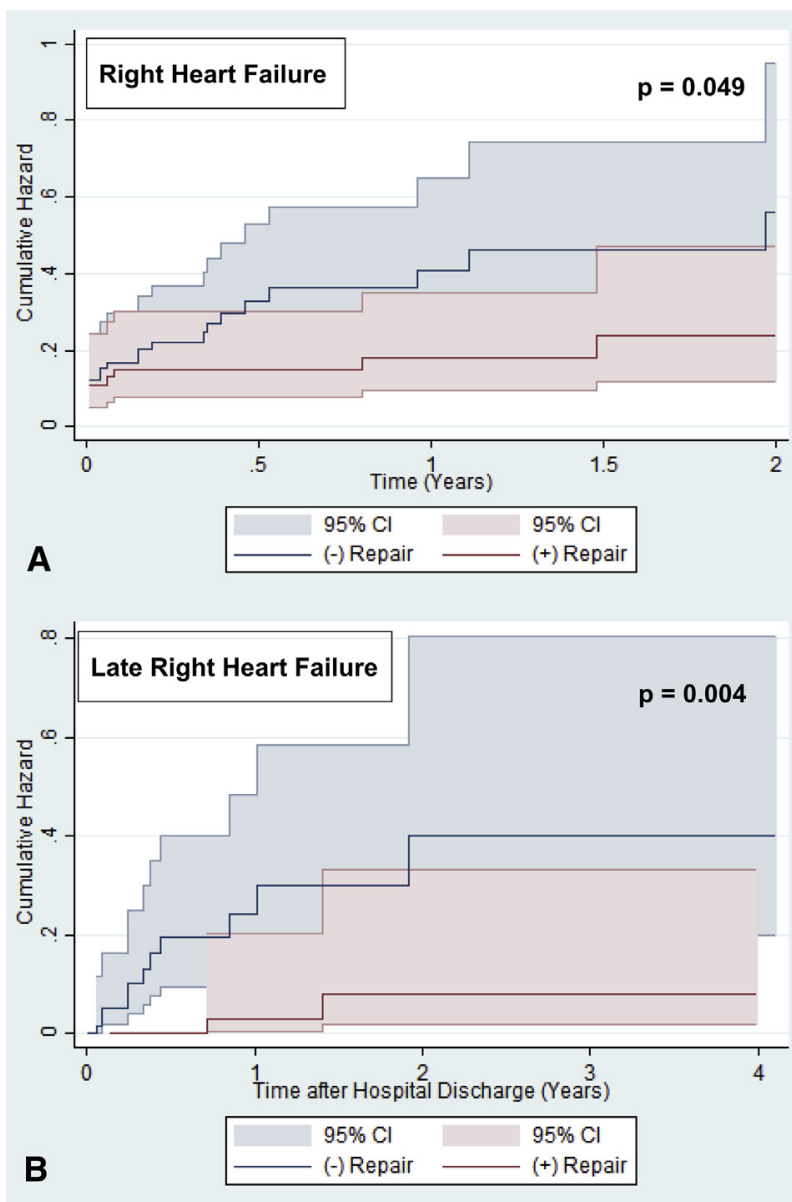

FIGURE 1. Nelson-Aalen cumulative hazard plot of postimplant adverse event in patients with mitral repair versus without repair. A, Right heart failure (during index hospitalization + late right heart failure). B, Late right heart failure. $95 \% \mathrm{CI}$, Confidence interval.

was observed in Group B (Figure 1, $A$ and $B$ ), whereas RHF during the index hospitalization was comparable between groups (Table E1). Overall, $5(9.6 \%)$ in Group A and 3 $(4.8 \%)$ in Group B received an RVAD. There was no difference regarding the occurrence of other adverse events (Figure $1, A$ and $B$, Figure E2, $A$ and $B$, Figure E3, $A$ and $B$, and Figure E4).

The estimated on-device survival at 2 years was $79.9 \%$ $(6.5 \%)$ and $68.8 \%(11.1 \%)(P=.83)$, and the overall survival at 2 years was $79.1 \%(6.0 \%)$ and $85.5 \%(4.5 \%)$ $(P=.40)$ in Group A and B, respectively (Figure 2 and Figure E5).

\section{Comparison of Postimplant MR Between Groups}

Significant postimplant residual MR was defined as at least moderate MR despite medical therapy, device decompression, and pump speed optimization. A total of 429 postimplant echocardiographic studies were available. Table E2

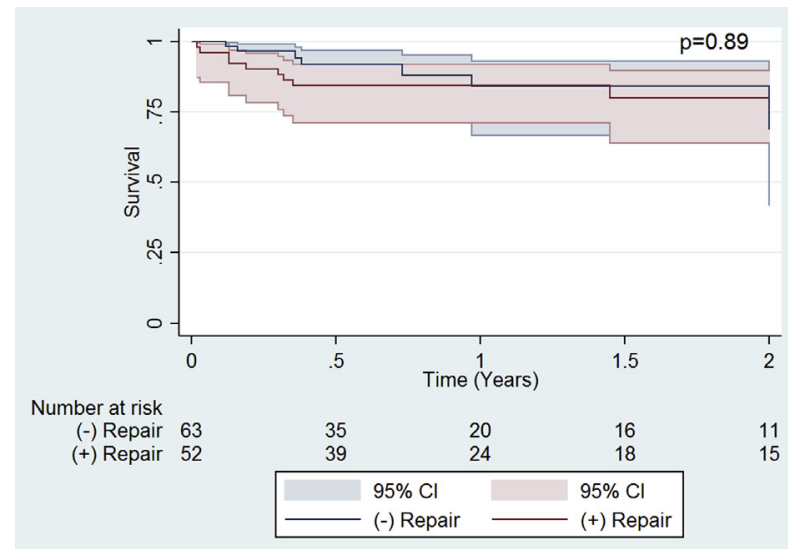

FIGURE 2. Kaplan-Meier curve for on-device survival at 2 years; comparison of patients with mitral repair versus without repair. 95\% $C I$, $95 \%$ Confidence interval.

demonstrates the number of echocardiographic studies remaining at each time point. Longitudinal changes in MR grades over time at time of/after index hospital discharge in each group are shown in Figure 3. At time of discharge, no patients in Group A had residual MR, whereas $20 \%$ in Group B $(P<.001)$ did. Approximately $30 \%$ of patients in the nonrepair group demonstrated significant residual MR consistently across the follow-up periods up to 2 postdevice years. MR appeared to be well controlled regardless of surgical technique (ring annuloplasty vs edge to edge). Furthermore, the longitudinal analysis using generalized mixed effects model showed the odds of developing a moderate/severe MR were $86 \%$ lower for patients who underwent repair versus those who did not $(P<.001)$ (Table 3$)$.

\section{Contributing Factors for Late RHF and Posttransplant Survival}

Among 105 patients (46 repaired and 59 nonrepaired) who were discharged alive, $9(8.6 \%)$, consisting of 1 $(2.2 \%)$ in Group $\mathrm{A}$ and $8(13.6 \%)$ in Group B $(P=.039)$, developed late RHF requiring a total of 13 readmissions (0.03 vs 0.15 readmissions per patient-year; $P=.011)$. All patients received intensified diuretic therapy, 4 received inotropic therapy, and 1 (1 out of $8 ; 12.5 \%)$ in Group B required an RVAD implantation. Further subgroup comparison stratified by the presence of tricuspid repair was also performed. The incidence of late RHF in each group was $3.0 \%$ (mitral repair alone; $\mathrm{n}=33$ ), $0 \%$ (mitral + tricuspid repair; $\mathrm{n}=10$ ), $11.1 \%$ (tricuspid repair alone; $\mathrm{n}=18$ ), and $12.5 \%$ (no mitral or tricuspid repair; $\mathrm{n}=40)$, respectively $(P=.34)$.

Clinical parameters before/at device insertion were analyzed to identify contributing factors for late RHF occurrence. Multivariable competing risks regression analysis revealed that blood urea nitrogen was a contributing factor 

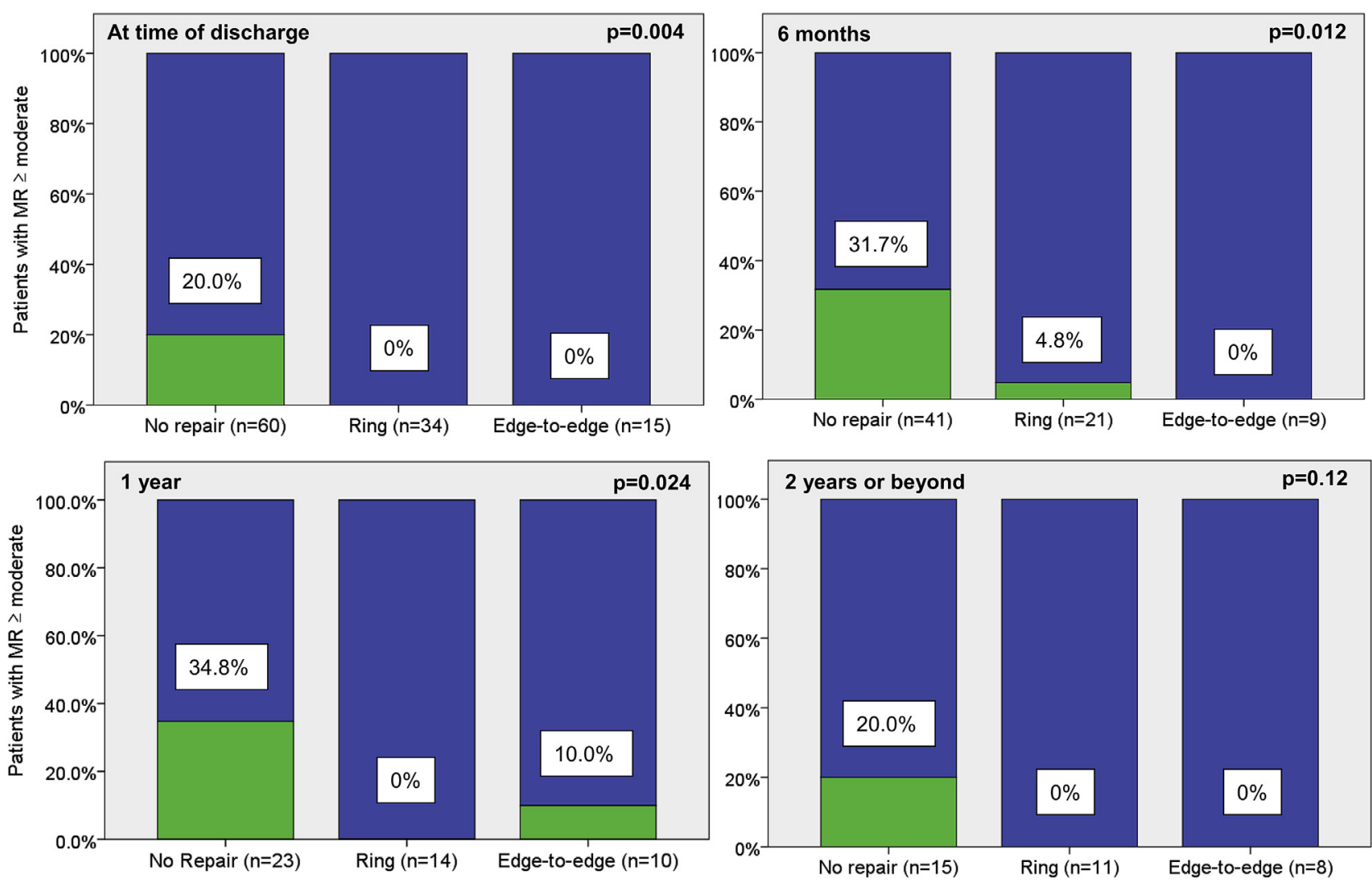

FIGURE 3. Proportion of patients with moderate or greater mitral regurgitation $(M R)$ postdevice implant at baseline pump speed at discharge, 6 months, 1 year, and 2 years or beyond.

(HR, 1.21 per 5-point increase; 95\% CI, 1.03-1.42; $P=.022)$, whereas mitral repair was a protective factor (HR, 0.15; 95\% CI, 0.028-0.85; $P=.031$ ) (Table 4). A list of variables entered in the analysis is shown in Table E3.

Among those 9 patients who developed late RHF, 6 patients underwent bridge to transplant. The 2-year survival after transplant was 33.3\% among these 6 patients. Two died of primary graft dysfunction/multiorgan failure and other two died of sepsis/multiorgan failure. In contrast, the 2-year survival among transplanted patients who did not experience late RHF was $93.3 \%$ (42 out of 45 ).

TABLE 3. Longitudinal analysis using generalized mixed effects model to assess the association between the treatment (mitral repair vs no repair) and mitral regurgitation moderate or greater following device insertion

\begin{tabular}{|c|c|c|c|}
\hline Variable & $\begin{array}{c}\text { Estimate } \pm \text { standard } \\
\text { error }\end{array}$ & $\begin{array}{l}\text { Odds ratio }(95 \% \\
\text { confidence interval) }\end{array}$ & $\begin{array}{c}P \\
\text { value }\end{array}$ \\
\hline Repair vs nonrepair & $-1.98 \pm 0.39$ & $0.14(0.06-0.30)$ & $<.001 *$ \\
\hline Time $\dagger$ & $0.05 \pm 0.09$ & $1.05(0.88-1.25)$ & .599 \\
\hline
\end{tabular}

*Statistically significant. †Time was fitted on the log scale.

\section{DISCUSSION}

The fact that late RHF was observed less frequently in the repaired patients, even compared with nonrepaired patients with baseline severe MR, clearly challenges the notion that concurrent mitral repair is unwarranted. We speculate that more controlled postimplant MR enables less challenging volume management postoperatively. Furthermore, having more controlled MR would be safer in cases of unexpected device failure (Video 1).

In contrast to the attention paid to aortic/tricuspid disease in patients with a CF-LVAD, mitral pathology has received less attention for surgical repair largely due to the reduction in left ventricular end-diastolic diameter and MR severity following device insertion. ${ }^{2,8,22}$ Furthermore, no previous studies have demonstrated uncorrected MR to be associated with worse survival. Stulak and colleagues ${ }^{22}$ reported on 491 patients among whom 189 had greater-thanmoderate MR and 302 had moderate MR or less. There was more favorable survival in patients with severe preimplant MR, suggesting lack of value of surgical repair. However, neither surgical control nor postimplant MR data were provided in their study. Another study with a smaller cohort, again without a surgical control group, demonstrated 
TABLE 4. Multivariable competing risks regression for contributors to late right heart failure among patients who were discharged from index hospitalization $(n=105)$. Competing events included death, transplant, and device removal

\begin{tabular}{lcc}
\hline \multicolumn{1}{c}{ Variable } & $\begin{array}{c}\text { Hazard ratio }(95 \% \\
\text { confidence interval) }\end{array}$ & $\boldsymbol{P}$ value \\
\hline Mitral repair & $0.15(0.028-0.85)$ & $.031^{*}$ \\
Blood urea nitrogen $\dagger$ & $1.21(1.03-1.42)$ & $.022^{*}$ \\
Tricuspid repair & $1.11(0.25-5.02)$ & .89 \\
Pulmonary vascular resistance & $1.08(0.79-1.50)$ & .63 \\
Female & $0.54(0.061-4.74)$ & .58 \\
\hline
\end{tabular}

*Statistically significant values $(P<.05)$. $†$ The hazard ratio for blood urea nitrogen is shown for 5-unit increment.

similar 1-year survival between patients with $(\mathrm{n}=13)$ and without $(n=64)$ significant postdevice implant MR. $^{2}$ Despite lack of surgical control groups across all of these studies, there has been a general consensus that preexisting MR does not require repair at device implantation, irrespective of its severity. Consequently, most centers presently avoid any procedures on regurgitant mitral valves. Meanwhile, there have been a few studies describing concurrent mitral repair from small cohorts of patients. Russo and colleagues ${ }^{23}$ examined the outcomes of transapical edge-to-edge mitral repair on 19 patients who underwent CF-LVAD placement. Taghavi and colleagues ${ }^{24}$ reported on 57 patients among whom $18(32 \%)$ received a repair and $3(5 \%)$ received a replacement. Although sample size and lack of clinical details limit interpretation of these study results, both demonstrated acceptable postoperative morbidity. Moreover, the latter showed greater postimplant decrease in pulmonary vascular resistance in the repair group. ${ }^{24}$ More recently, Tanaka and colleagues ${ }^{25}$ demonstrated that patients whose MR was corrected with valve repair or replacement had significantly better hemodynamic profiles postimplant compared with patients whose MR spontaneously resolved with CF-LVAD implantation alone.

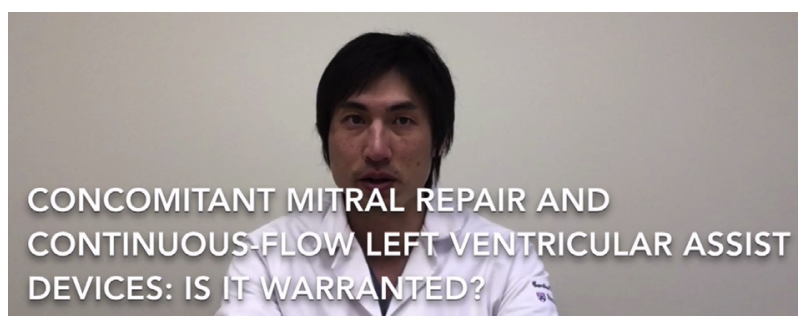

VIDEO 1. Introduction and brief overview of the present study by one of authors. Video available at: http://www.jtcvsonline.org/article/S00225223(17)30840-1/addons.
In addition, heart failure-related readmission rate was observed less frequently in the repaired group. Their results are partially in line with findings in the present study.

Although the severity of MR has been demonstrated to regress without repair, CF-LVAD unloading may not be sufficient to counteract functional MR in a subset of patients. Kitada and colleagues ${ }^{2}$ reviewed 82 patients who underwent CF-LVAD insertion after excluding patients with organic lesions. More than $30 \%$ of patients continued to have significant MR despite device support. Although MR usually decreases with higher speeds, it appears that preoperative posterior displacement of mitral leaflets is associated with persistent MR. Their results are compatible with the present study, in which $20 \%$ to $35 \%$ of patients in the nonrepair group demonstrated persistent MR postimplant.

Pump speed is determined based on optimal LV unloading and severity of MR while avoiding complications related to high pump flow. The MR degree significantly varies with pump speed and hemodynamic parameters during echocardiography. ${ }^{11}$ Furthermore, there is a trade-off relationship between pump speed and RV function. By increasing pump speed, which is used to reduce MR degree, RV function and aortic valve opening can be compromised. The degree of septal deviation may predict the development of RV failure during CF-LVAD support. ${ }^{26,27}$ With reduced LV pressures, bowing of the interventricular septum away from the RV into the decompressed $\mathrm{LV}$ can alter RV shape and size and reduce the efficiency of RV contraction. ${ }^{25}$ The RV may be further challenged by the increased preload provided by the device effect on increased systemic blood flow, which is increased at higher pump-speed settings. ${ }^{28}$ Again, pump speed has such dynamic characteristics determined by multiple factors. Optimal pump speed widely varies in each individual and therefore the mean pump speed as a group (repair or nonrepair) has little clinical relevance, although repaired patients with a HeartMate II device demonstrated lower mean pump speed in the present study. We suspect the relatively small sample size of the HeartWare cohort (11 patients in Group A and 7 patients in Group B) might be insufficient to detect significant differences in pump speed. We postulate mitral repair might have lowered pump speed, which would have been the amount of speed to be added to suppress MR degree. Uriel and colleagues ${ }^{11}$ conducted a study to evaluate the utility of ramp tests for assessing ventricular decompression in HeartWare ventricular assist device patients. ${ }^{11}$ The interaction of left ventricular end diastolic diameter with mitral repair suggests that ventricular geometry influences the device unloading properties. By decreasing the size of the mitral annulus, the mitral repair amplifies the effects of ventricular decompression. The authors suggested mitral repair might be indicated if lower speeds are necessary to preserve aortic valve integrity or maintain pulsatility within the peripheral circulation. 
The optimal repair method remains unclear. In the present study, 2 techniques, consisting of annuloplasty and edge-toedge repair, were performed. Although the technical feasibility and durability of each technique appeared acceptable, no conclusion could be drawn from the data regarding the choice of repair technique. The criticism edge-to-edge repair alone without annuloplasty is suboptimal durability ${ }^{17}$ in non-CF-LVAD settings. On the contrary, there is a paucity of data specifically related to patients supported by CF-LVAD. In addition, in cases of severe annular calcification annular manipulation should be avoided. Our data confirmed the midterm durability of concurrent edge-toedge repair in patients who underwent CF-LVAD insertion. Although an advantage of these repair techniques includes procedural simplicity, concurrent mitral repair is not without risk. In fact, CPB time was significantly greater in the repair cohort. However, bleeding, blood product use, and vasoactive-inotropic score were similar. Additionally, on-device and overall survival were comparable between groups.

\section{Study Limitations}

First, our investigation is limited by the retrospective nature. Second, the serial follow-up echocardiographic studies, which can be often influenced by hemodynamic parameters, were performed in a variety of clinical settings such as in the intensive care unit and outpatient clinic. Third, the decision for repair was made by surgeons based on various clinical characteristics and repair technique in each patient was not selected randomly, introducing further selection bias into the results and making our conclusion not convincing. Furthermore, there were no data correlating repaired/nonrepaired patients with functional capacity testing or hemodynamic parameters due to lack of a postimplant cardiac catheterization. Fourth, many underwent concomitant aortic/tricuspid valve repairs in addition to mitral repair. Lastly, mitral repair was more frequently performed in relatively recent patients simply because there were few destination therapy patients before 2007 in the present study population. Although these potential confounders, including year of device implantation and other valve repairs, were all entered into the multivariable analysis and demonstrated no association with late RHF. Clinical effect by these factors to the outcomes could not be completely eliminated.

\section{CONCLUSIONS}

Concurrent mitral repair, irrespective of technique, appears to be durable in controlling MR postdevice implant. Although this study has a number of limitations, the fact that mitral repair was associated with less frequent occurrence of late RHF, which appears to be a significant factor for worse posttransplant survival, ${ }^{15}$ is particularly noteworthy, cautioning against the concept that concurrent mitral repair is unnecessary. Considering our observation, further studies are truly needed to validate our results and clarify the unanswered questions in this society.

\section{Conflict of Interest Statement}

Y.N. has been a consultant for the Thoratec Corporation. All other authors have nothing to disclose with regard to commercial support.

\section{References}

1. Kirklin JK, Naftel DC, Pagani FD, Kormos RL, Stevenson LW, Blume ED, et al. Seventh INTERMACS annual report: 15,000 patients and counting. J Heart Lung Transplant. 2015;34:1495-504.

2. Kitada S, Kato TS, Thomas SS, Conwell SD, Russo C, Di Tullio MR, et al. Preoperative echocardiographic features associated with persistent mitral regurgitation after left ventricular assist device implantation. J Heart Lung Transplant. 2013;32:897-904.

3. Fukuhara S, Takeda K, Chiuzan C, Han J, Polanco AR, Yuzefpolskaya M, et al. Concomitant aortic valve repair with continuous-flow left ventricular assist devices: Results and implications. J Thorac Cardiovasc Surg. 2016;151:201-10.e2.

4. Han J, Takeda K, Takayama H, Kurlansky PA, Mauro CM, Colombo PC, et al. Durability and clinical impact of tricuspid valve procedures in patients receiving a continuous-flow left ventricular assist device. J Thorac Cardiovasc Surg. 2016; 151:520-7.e1.

5. Patel JB, Borgeson DD, Barnes ME, Rihal CS, Daly RC, Redfield MM. Mitral regurgitation in patients with advanced systolic heart failure. J Card Fail. 2004;10:285-91

6. Kono T, Sabbah HN, Rosman H, Alam M, Jafri S, Goldstein S. Left ventricular shape is the primary determinant of functional mitral regurgitation in heart failure. J Am Coll Cardiol. 1992;20:1594-8.

7. Sabbah HN, Kono T, Rosman H, Jafri S, Stein PD, Goldstein S. Left ventricular shape: a factor in the etiology of functional mitral regurgitation in heart failure. Am Heart J. 1992;123:961-6.

8. Wang TS, Hernandez AF, Felker GM, Milano CA, Rogers JG, Patel CB. Valvular heart disease in patients supported with left ventricular assist devices. Circ Heart Fail. 2014; 7:215-22.

9. Alba AC, Rao V, Ross HJ, Jensen AS, Sander K, Gustafsson F, et al. Impact of fixed pulmonary hypertension on post-heart transplant outcomes in bridge-totransplant patients. J Heart Lung Transplant. 2010;29:1253-8.

10. Uriel N, Morrison KA, Garan AR, Kato TS, Yuzefpolskaya M, Latif F, et al Development of a novel echocardiography ramp test for speed optimization and diagnosis of device thrombosis in continuous-flow left ventricular assist devices: the Columbia ramp study. J Am Coll Cardiol. 2012;60:1764-75.

11. Uriel N, Levin AP, Sayer GT, Mody KP, Thomas SS, Adatya S, et al. Left ventricular decompression during speed optimization ramps in patients supported by CF-LVADS: device specific performance characteristics and impact for diagnostic algorithms. J Card Fail. 2015;21:785-91.

12. Zoghbi WA, Enriquez-Sarano M, Foster E, Grayburn PA, Kraft CD, Levine RA et al. Recommendations for evaluation of the severity of native valvular regurgitation with two-dimensional and Doppler echocardiography. J Am Soc Echocardiogr. 2003;16:777-802.

13. Topilsky Y, Hasin T, Oh JK, Borgeson DD, Boilson BA, Schirger JA, et al. Echocardiographic variables after left ventricular assist device implantation associated with adverse outcome. Circ Cardiovasc Imaging. 2011;4:648-61.

14. INTERMACS adverse event definitions: Adult and pediatric patients. Available at: https://www.uab.edu/medicine/intermacs/images/protocol_4.0/protocol_4.0_ MoP/Appendix_A_INTERMACS_AE_Definitions_05152013.docx. Accessed April 25, 2017.

15. Takeda K, Takayama H, Colombo PC, Jorde UP, Yuzefpolskaya M, Fukuhara S et al. Late right heart failure during support with continuous-flow left ventricular assist devices adversely affects post-transplant outcome. J Heart Lung Transplant. 2015;34:667-74 
16. Takeda K, Takayama H, Colombo PC, Yuzefpolskaya M, Fukuhara S, Han J, et al. Incidence and clinical significance of late right heart failure during continuous-flow left ventricular assist device support. J Heart Lung Transplant. 2015;34:1024-32.

17. Maisano F, Caldarola A, Blasio A, De Bonis M, La Canna G, Alfieri O. Midterm results of edge-to-edge mitral valve repair without annuloplasty. J Thorac Cardiovasc Surg. 2003;126:1987-97.

18. Takayama H, Yang JA, Naka Y. Tips on tuning each device: technical pearls. Cardiol Clin. 2011;29:551-6.

19. Fine JP, Gray RJ. A proportional hazards model for the subdistribution of a competing risk. J Am Stat Assoc. 1999;94:496-509.

20. Ware JH. Linear models for longitudinal continuous data. In: Fitzmaurice GM, Laird NM, Ware JH, eds. Applied longitudinal analysis. 2nd ed. Hoboken: John Wiley \& Sons; 2011:95.

21. Nguyen HV, Havalad V, Aponte-Patel L, Murata AY, Wang DY, Rusanov A, et al. Temporary biventricular pacing decreases the vasoactive-inotropic score after cardiac surgery: a substudy of a randomized clinical trial. J Thorac Cardiovasc Surg. 2013;146:296-301.

22. Stulak JM, Tchantchaleishvili V, Haglund NA, Davis ME, Schirger JA, Cowger JA, et al. Uncorrected pre-operative mitral valve regurgitation is not associated with adverse outcomes after continuous-flow left ventricular assist device implantation. J Heart Lung Transplant. 2015;34:718-23.

23. Russo MJ, Merlo A, Johnson EM, Akhter S, McCarney S, Steiman J, et al. Transapical approach for mitral valve repair during insertion of a left ventricular assist device. Sci World J. 2013;2013:925310.
24. Taghavi S, Hamad E, Wilson L, Clark R, Jayarajan SN, Uriel N, et al. Mitral valve repair at the time of continuous flow left ventricular assist device implantation confers meaningful decrement in pulmonary vascular resistance. ASAIO J. 2013;59:469-73.

25. Tanaka A, Onsager D, Song T, Cozadd D, Kim G, Sarswat N, et al. Surgically corrected mitral regurgitation during left ventricular assist device implantation is associated with low recurrence rate and improved midterm survival. Ann Thorac Surg. 2017;103:725-33.

26. Estep JD, Chang SM, Bhimaraj A, Torre-Amione G, Zoghbi WA, Nagueh SF. Imaging for ventricular function and myocardial recovery on nonpulsatile ventricular assist devices Jerry D. Circulation. 2012;125: 2265-77.

27. Neragi-Miandoab S, Goldstein D, Bello R, Michler R, D’Alessandro D. Right ventricular dysfunction following continuous flow left ventricular assist device placement in 51 patients: predicators and outcomes. J Cardiothorac Surg. 2012;7:60.

28. Kormos RL, Teuteberg JJ, Pagani FD, Russell SD, John R, Miller LW, et al. Right ventricular failure in patients with the HeartMate II continuous-flow left ventricular assist device: incidence, risk factors, and effect on outcomes. J Thorac Cardiovasc Surg. 2010;139:1316-24.

Key Words: mitral valve repair, continuous-flow left ventricular assist device, right heart failure 


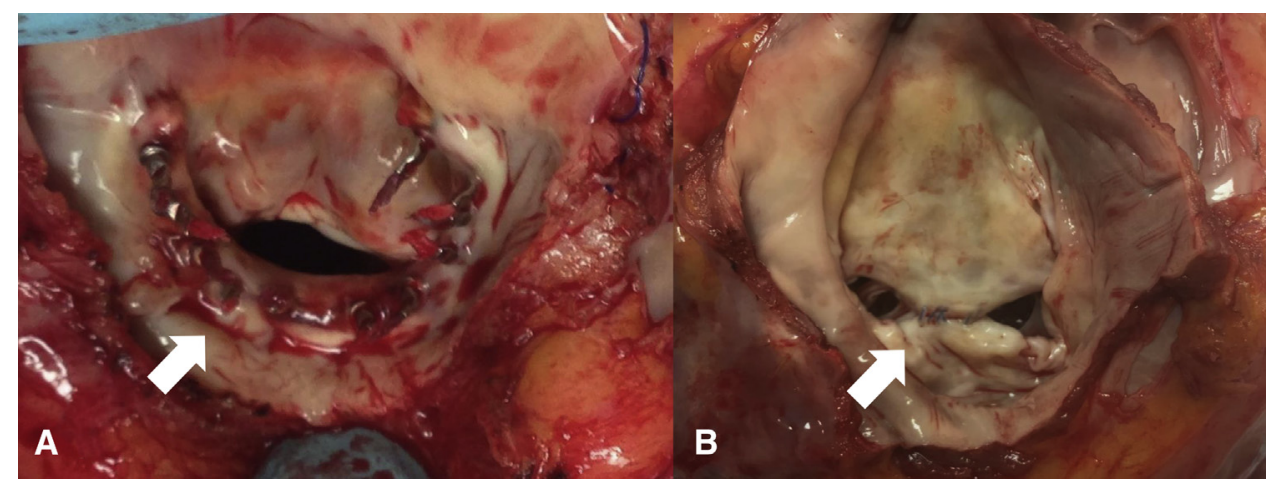

FIGURE E1. Mitral valves from explanted hearts of patients who received a concomitant mitral repair. A, Cosgrove-Edwards annuloplasty ring (Edwards Lifesciences, Irvine, Calif) (arrow). B, Edge-to-edge repair (arrow).
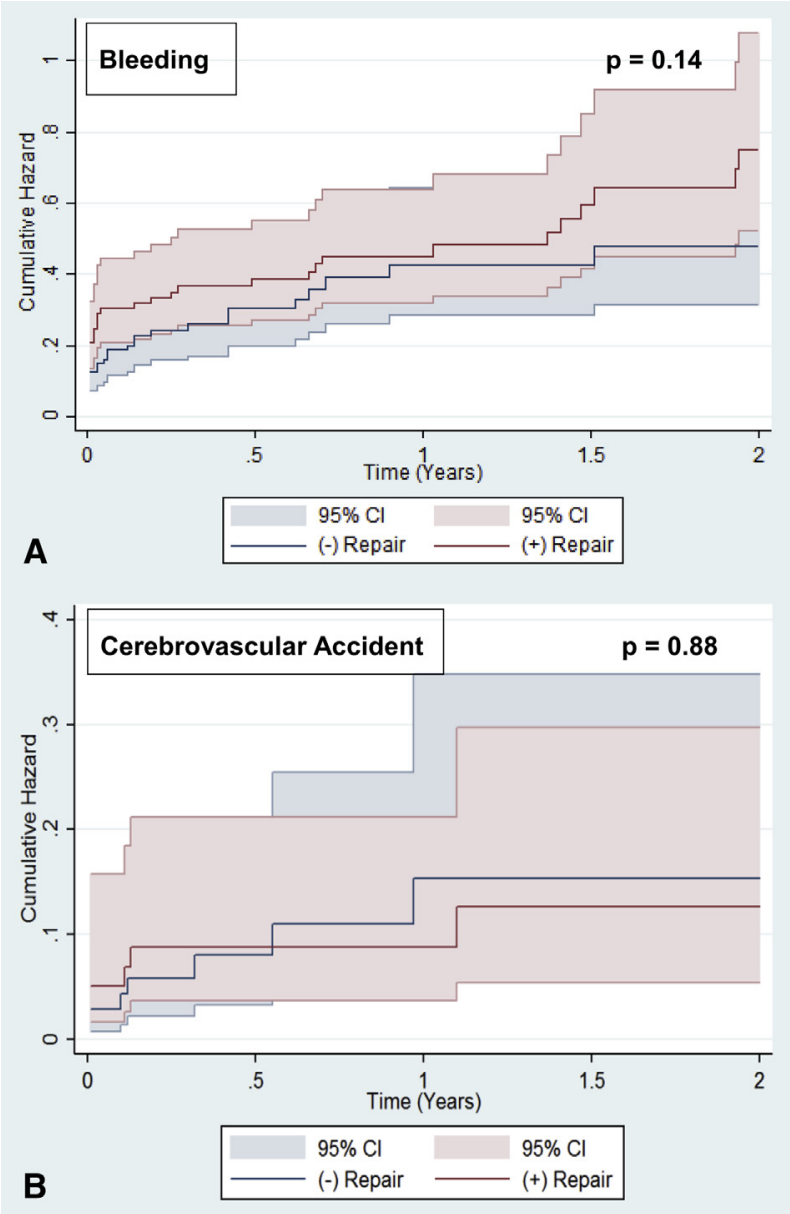

FIGURE E2. Nelson-Aalen cumulative hazard plot of postimplant adverse event in patients with mitral repair versus without repair. A, Bleeding. B, Cerebrovascular accident. 95\% CI, 95\% Confidence interval.
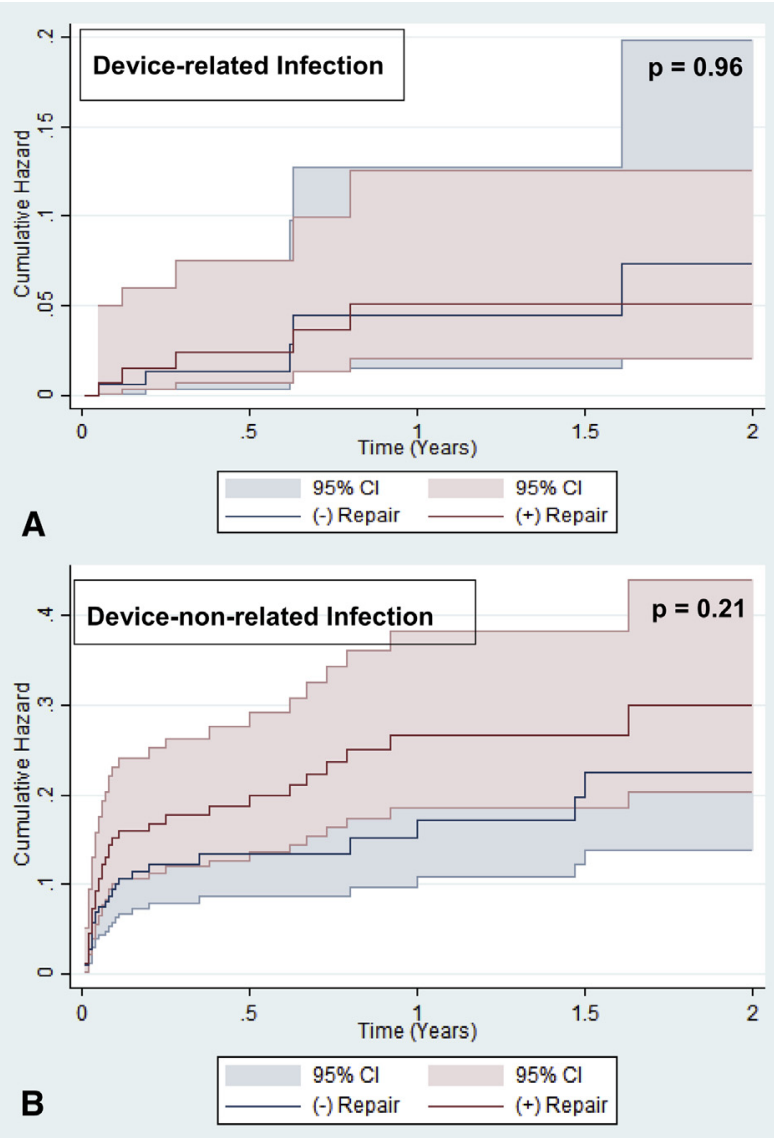

FIGURE E3. Nelson-Aalen cumulative hazard plot of postimplant adverse event in patients with mitral repair versus without repair. A, Device-related infection. B, Device-nonrelated infection. 95\% CI, 95\% Confidence interval. 


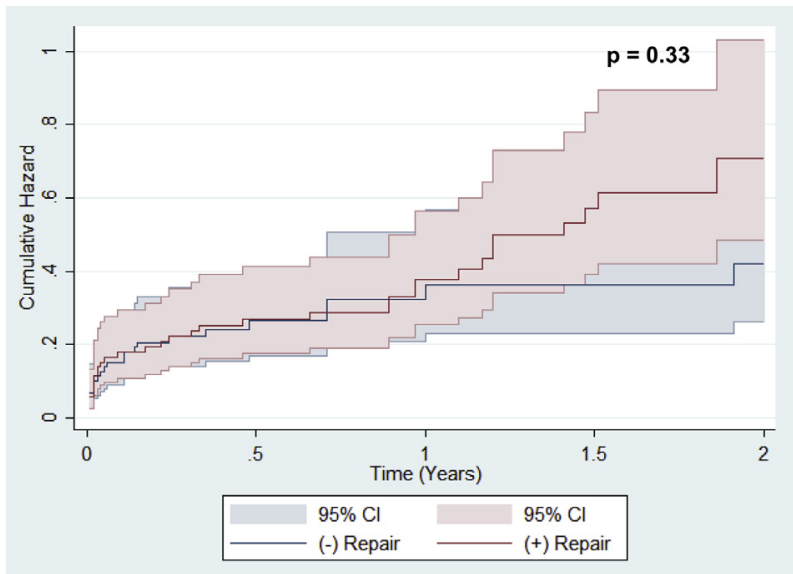

FIGURE E4. Nelson-Aalen cumulative hazard plot of postimplant ventricular arrhythmia occurrence in patients with mitral repair versus without repair. $95 \% \mathrm{CI}, 95 \%$ Confidence interval.

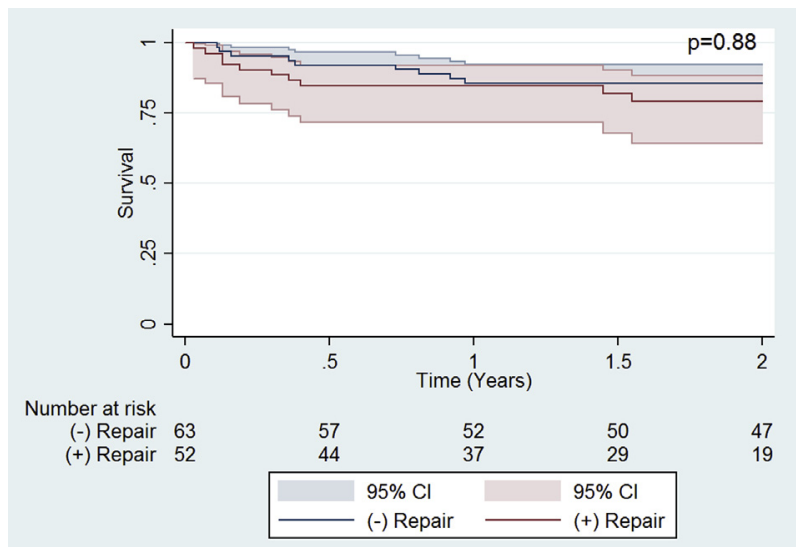

FIGURE E5. Kaplan-Meier curve for overall survival at 2 years. $95 \% C I$, 95\% Confidence interval. 
TABLE E1. Early and late postimplantation follow-up data

\begin{tabular}{|c|c|c|c|}
\hline Variable & $(+)$ Repair $(n=52)$ & $(-)$ Repair $(n=63)$ & $P$ value \\
\hline 30-d mortality & $2(3.8)$ & 0 & .20 \\
\hline In-hospital mortality & $6(11.5)$ & $2(3.2)$ & .14 \\
\hline \multicolumn{4}{|l|}{ Intensive care unit stay } \\
\hline Days & $12.6 \pm 17.4$ & $9.6 \pm 5.4$ & .24 \\
\hline Median (interquartile range) & $7.0(5.0-11.0)$ & $7.0(5.0-11.5)$ & \\
\hline \multicolumn{4}{|l|}{ Hospital stay } \\
\hline Days & $41.3 \pm 54.0$ & $34.2 \pm 34.7$ & .39 \\
\hline Median (interquartile range) & $28.5(21.0-42.5)$ & $26.0(20.0-38.0)$ & \\
\hline \multicolumn{4}{|c|}{ Predischarge pump speed, RPM $(\mathrm{n}=98)$} \\
\hline HeartMate II $(\mathrm{n}=80)^{*}, \uparrow$ & $8931 \pm 460(\mathrm{n}=35)$ & $9200 \pm 451(n=45)$ & .010 \\
\hline HeartWare $(\mathrm{n}=18) \ddagger$ & $2522 \pm 92(\mathrm{n}=11)$ & $2594 \pm 133(\mathrm{n}=7)$ & .19 \\
\hline Transplanted* & $17(32.7)$ & $43(68.3)$ & $<.001$ \\
\hline \multicolumn{4}{|l|}{ Postoperative complications } \\
\hline Acute kidney injury & $11(21.2)$ & $8(12.7)$ & .22 \\
\hline CVVHD & $5(9.6)$ & $2(3.2)$ & .15 \\
\hline Bleeding requiring re-exploration & $13(25.0)$ & $10(15.9)$ & .22 \\
\hline CVA & $4(7.7)$ & $2(3.2)$ & .41 \\
\hline Urinary tract infection & $10(19.2)$ & $7(11.1)$ & .22 \\
\hline Sepsis & $8(15.4)$ & $4(6.3)$ & .12 \\
\hline Atrial fibrillation/flutter & $15(28.8)$ & $17(27.0)$ & .82 \\
\hline $\mathrm{VT} / \mathrm{VF}$ & $17(32.7)$ & $15(23.8)$ & .29 \\
\hline RHF & $8(15.4)$ & $12(19.0)$ & .61 \\
\hline
\end{tabular}

Values are presented as n (\%) unless otherwise noted. $C V V H D$, Continuous venovenous hemodialysis; $C V A$, cerebrovascular accident; $V T$, ventricular tachycardia; $V F$, ventricular fibrillation; $R H F$, right heart failure. *Statistically significant values $(P<.05)$. $\dagger$ Thoratec Corporation, Pleasanton, Calif. $\ddagger$ HeartWare, Framingham, Mass.

TABLE E2. The number of patients and corresponding echocardiographic studies remaining at each time point

\begin{tabular}{|c|c|c|c|c|c|c|c|c|}
\hline \multirow[b]{2}{*}{ Study variable } & \multicolumn{8}{|c|}{ Time, $\mathbf{y}$} \\
\hline & $\mathbf{0}$ & 0.5 & 1.0 & 1.5 & 2.0 & 2.5 & 3.0 & 3.5 \\
\hline \multicolumn{9}{|l|}{ (-) Repair } \\
\hline No. of patients & 63 & 35 & 21 & 16 & 11 & 10 & 8 & 5 \\
\hline No. of studies & 225 & 78 & 47 & 29 & 20 & 15 & 12 & 10 \\
\hline \multicolumn{9}{|l|}{ (+) Repair } \\
\hline No. of patients & 52 & 43 & 30 & 20 & 15 & 12 & 7 & 4 \\
\hline No. of studies & 204 & 86 & 49 & 32 & 21 & 10 & 3 & 0 \\
\hline
\end{tabular}


TABLE E3. List of variables entered into the Cox regression analysis

\begin{tabular}{|c|c|}
\hline Year (2004-2007, 2008-2011, 2012-2015) & Gender \\
\hline Age & Race/ethnicity \\
\hline Hypertension & Dyslipidemia \\
\hline Chronic kidney disease & COPD \\
\hline Smoking & Diabetes \\
\hline Carotid disease & Peripheral arterial disease \\
\hline Hemodialysis & Height \\
\hline Weight & BMI \\
\hline Previous sternotomy & IABP \\
\hline BSA & Prior stroke \\
\hline Etiology of heart failure (ischemic, dilated cardiomyopathy, others) & AICD \\
\hline Left ventricular ejection fraction & Moderate to severe $\mathrm{LVH}$ \\
\hline Baseline left ventricular end-diastolic diameter & Baseline left ventricular end-systolic diameter \\
\hline Vasoactive-inotropic score & INTERMACS $1 / 2$ \\
\hline Supported with ECMO at time of CF-LVAD implantation & Supported with short-term VAD at time of CF-LVAD implantation \\
\hline Uncorrected tricuspid regurgitation & Uncorrected mitral regurgitation \\
\hline Concomitant right ventricular assist device implantation & Concomitant aortic valve closure \\
\hline Concomitant aortic valve repair & Concomitant aortic valve replacement \\
\hline Concomitant mitral repair & Concomitant tricuspid repair \\
\hline Concomitant tricuspid replacement & Cardiopulmonary bypass time \\
\hline Device intent (BTT, DT) & Packed red blood cell transfusion \\
\hline Platelet transfusion & Fresh frozen plasma transfusion \\
\hline Baseline sodium & Baseline creatinine \\
\hline Baseline BUN & Baseline ALT \\
\hline Baseline AST & Baseline ALP \\
\hline Baseline bilirubin & Baseline INR \\
\hline Baseline albumin & Systolic blood pressure \\
\hline Diastolic blood pressure & Mean pulmonary artery pressure \\
\hline Pulmonary vascular resistance & Transpulmonary gradient \\
\hline Systolic blood pressure & Device brand (HeartMate II*, HeartWare VAD System + , others) \\
\hline Mean arterial blood pressure & Central venous pressure \\
\hline Pulmonary artery wedge pressure & Cardiac output, $\mathrm{L} / \mathrm{min}$ \\
\hline \multicolumn{2}{|l|}{ HeartMate II* risk score } \\
\hline
\end{tabular}

